\title{
Children grow and horses race: is the adiposity rebound a critical period for later obesity?
}

\section{TJ Cole*}

\author{
Address: Centre for Paediatric Epidemiology and Biostatistics, Institute of Child Health, London, UK \\ Email: TJ Cole* - tim.cole@ich.ucl.ac.uk \\ * Corresponding author
}

This article is available from: http://www.biomedcentral.com/|47I-243I/4/6

(C) 2004 Cole; licensee BioMed Central Ltd. This is an Open Access article: verbatim copying and redistribution of this article are permitted in all media for any purpose, provided this notice is preserved along with the article's original URL.

\begin{abstract}
Background: The adiposity rebound is the second rise in body mass index that occurs between 3 and 7 years. An early age at adiposity rebound is known to be a risk factor for later obesity. The aim here is to clarify the connection between the age at rebound and the corresponding pattern of body mass index change, in centile terms, so as to better understand its ability to predict later fatness.

Discussion: Longitudinal changes in body mass index during adiposity rebound, measured both in original $\left(\mathrm{kg} / \mathrm{m}^{2}\right)$ and standard deviation (SD) score units, are studied in five hypothetical subjects. Two aspects of the body mass index curve, the body mass index centile and the rate of body mass index centile crossing, determine a child's age at rebound. A high centile and upward centile crossing are both associated separately with an early rebound, while a low centile and/or downward centile crossing correspond to a late rebound. Early adiposity rebound is a risk factor for later fatness because it identifies children whose body mass index centile is high and/or crossing upwards. Such children are likely to have a raised body mass index later in childhood and adulthood. This is an example of Peto's "horse racing effect". The association of centile crossing with later obesity is statistical not physiological, and it applies at all ages not just at rebound, so adiposity rebound cannot be considered a critical period for future obesity. Body mass index centile crossing is a more direct indicator of the underlying drive to fatness.
\end{abstract}

Summary: An early age at adiposity rebound predicts later fatness because it identifies children whose body mass index centile is high and/or crossing upwards. Such children are likely to have a raised body mass index later. Body mass index centile crossing is more direct than the timing of adiposity rebound for predicting later fatness.

\section{Background}

There is continuing interest and concern about the worldwide epidemic of child obesity, particularly its role in the development of later obesity and adult chronic disease. $[1,2]$ The adiposity rebound is the second rise in adiposity, as measured by body mass index (BMI = weight/ height ${ }^{2}$, which occurs between 3 and 7 years of age in individual children. [3] It corresponds to fat cells starting to increase in number after an earlier phase of increasing then decreasing in size. [4] In an important paper Rolland-Cachera [3] noted that the age the rebound occurs (the age at adiposity rebound) predicts later fatness, an earlier rebound predicting greater fatness in adolescence [3] and adulthood. [4-6] This ability to predict adult 
fatness in early childhood has led other authors to suggest that the adiposity rebound is a critical period of growth. $[7,8]$

Yet there remains some scepticism about the value of the adiposity rebound, and uncertainty as to what exactly it measures. Dietz for example has termed it an epiphenomenon [9]. Also the association of the age at rebound with later fatness vanishes once the child's BMI at age 7 is adjusted for [10]. The aim of this study is to relate the age at adiposity rebound to the corresponding pattern of BMI centile change, to see whether the adiposity rebound's prediction of later fatness makes it a critical period of growth.

\section{Discussion Effect of BMI centile}

The age at adiposity rebound is defined as the age (beyond infancy) when an individual's BMI is at a minimum [3]. Each centile curve on the BMI centile chart shows the pattern for a hypothetical child tracking along that centile. For example on the British 1990 girls chart [11] the age at rebound is 5.5 years on the median, but ranges from 3.3 on the $99.6^{\text {th }}$ centile to 6.7 on the $0.4^{\text {th }}$ centile (Figure 1 ). Each centile curve has its own age at rebound, the higher the centile the earlier the rebound. [9] So for a child tracking along the $99.6^{\text {th }}$ centile, rebound occurs 2.2 years earlier than for a median-tracking child, while for a child on the $0.4^{\text {th }}$ centile it is 1.2 years later.

\section{Effect of BMI centile crossing}

Specifying the age at rebound for an individual child requires at least three BMI measurements spread over several years: one before, one at or near rebound and one after. The middle measurement is smaller in value than the other two, and its age of measurement may be earlier or later than the true (unobserved) age at rebound.

For simplicity the analysis here focuses on just three measurements per child covering a 4-year period, and assumes that the first and third measurements have the same value. This is always possible in theory by timing the measurements appropriately.

Figure 2 shows such triplets of measurements for five girls labelled A to E, superimposed on the British BMI chart. Their hypothetical data are selected to cover the range of $\mathrm{BMI}$ and age at rebound. Ignore for now the data for older girls.

The age at rebound depends primarily on the ages of the outer two measurements, and their mean age (assuming a symmetric BMI curve [12]) is an unbiased estimate of the age at rebound. The girls in Figure 2 are labelled in increasing order of age at rebound: A, B, C, D and E.
Consider now the centiles corresponding to the measurements. Each subject's outer two BMI values are the same yet their centiles differ. For A and B the third centile is higher than the first (corresponding to upward centile crossing), for $\mathrm{D}$ and $\mathrm{E}$ the reverse is true (downward centile crossing), and only for $\mathrm{C}$ are the two centiles the same. The reason is readily apparent - for A and B the background centile curves are falling with time, for $\mathrm{D}$ and $\mathrm{E}$ they are rising, and for $\mathrm{C}$ they are effectively flat. The direction of centile change depends only on whether the child's age at rebound is earlier or later than the age at rebound corresponding to her BMI centile at rebound.

\section{BMI centile and SD score}

Figure 3 confirms this centile crossing interpretation. The BMI triplets of Figure 2 are redrawn on the SD score scale, so that the nine centile curves now appear as horizontal and equally spaced straight lines [13]. Figure 3 shows that the BMI values for each girl were chosen to represent a constant rate of centile crossing: rising for $\mathrm{A}$ and $\mathrm{B}$, falling for $\mathrm{D}$ and $\mathrm{E}$, and flat for $\mathrm{C}$. The ages at rebound for $\mathrm{A}$ and $\mathrm{B}$ are similar (Figure 2) yet their centiles and centile rate rises are very different (Figure 3 ). $B$ starts below the $2^{\text {nd }}$ centile while A starts above the $98^{\text {th }}$ centile, and B's centile rate rise is more than four times that for A. This reflects B's age at rebound being more than two years earlier than the $2^{\text {nd }}$ centile age at rebound. A's is by contrast only two months earlier than the $99^{\text {th }}$ centile age at rebound.

To see how the adiposity rebound distorts centile crossing on the BMI chart, Figures 2 and 3 also show the centile patterns of girls A to E shifted to a start age of 13 years, where they are labelled AA to EE respectively. Figure 2 emphasises that their wide spectrum of centile crossing patterns is obscured at rebound by the falling then rising centile curves, and are much more obvious later in childhood.

Figure 2 also shows that despite the linear pattern of centile crossing, most of the BMI triplets are almost flat at rebound. (And there is an optical illusion which suggests - incorrectly - that the outer two measurements are not the same.) This underlines the difficulty of estimating the age at rebound accurately in individual cases, particularly when measurement error is present. By contrast the rate of centile crossing needs just two BMI measurements a year or two apart to estimate it.

There is a clear and direct link between the age at rebound on the one hand, and a combination of BMI centile and BMI centile crossing on the other. An early rebound corresponds to a high centile and/or upward centile crossing, and a late rebound to a low centile and/or downward centile crossing. Furthermore the rate of centile crossing increases with the time gap between the child's own age at 


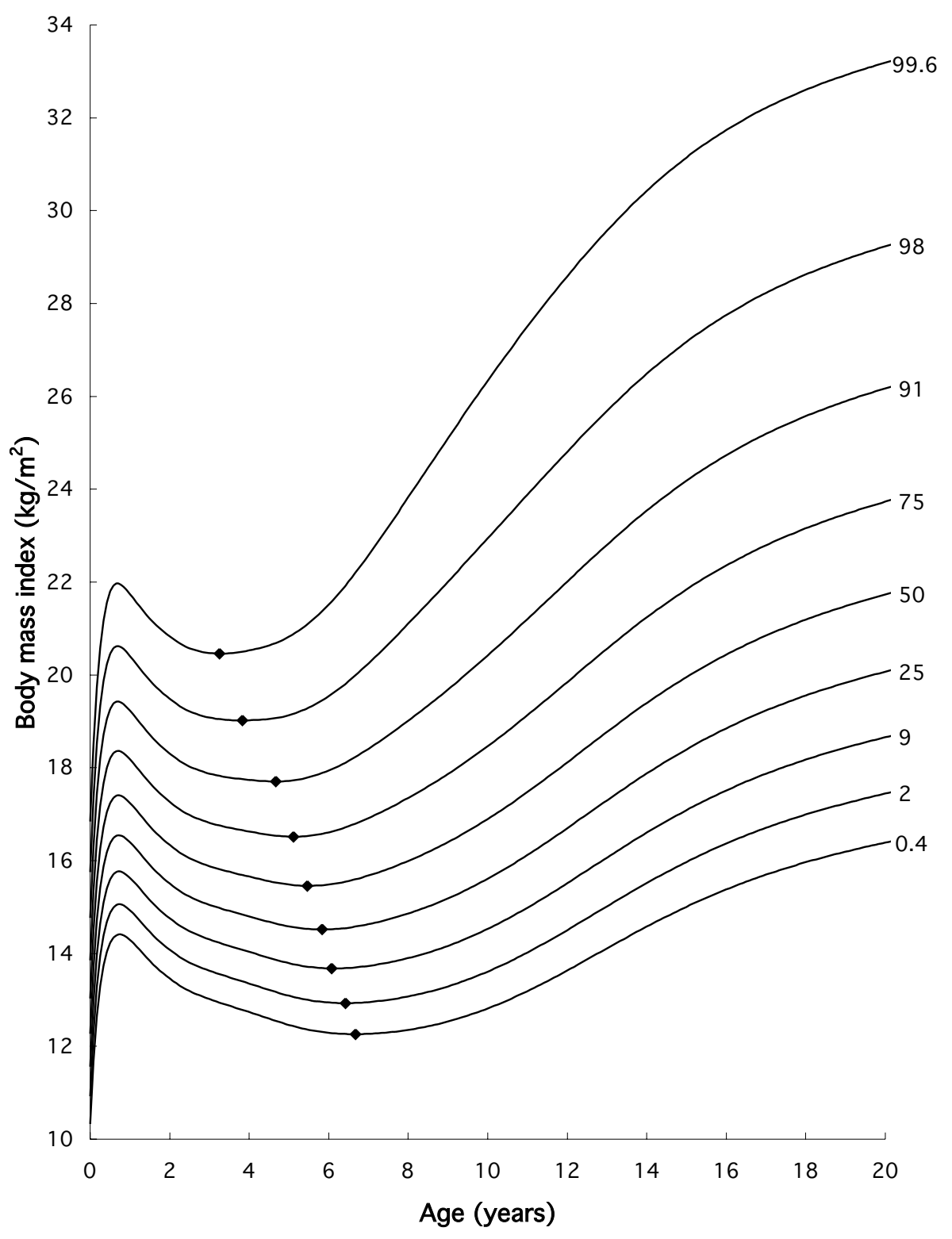

Figure I

British 1990 girls BMI chart The age at adiposity rebound is inversely related to the BMI centile. 


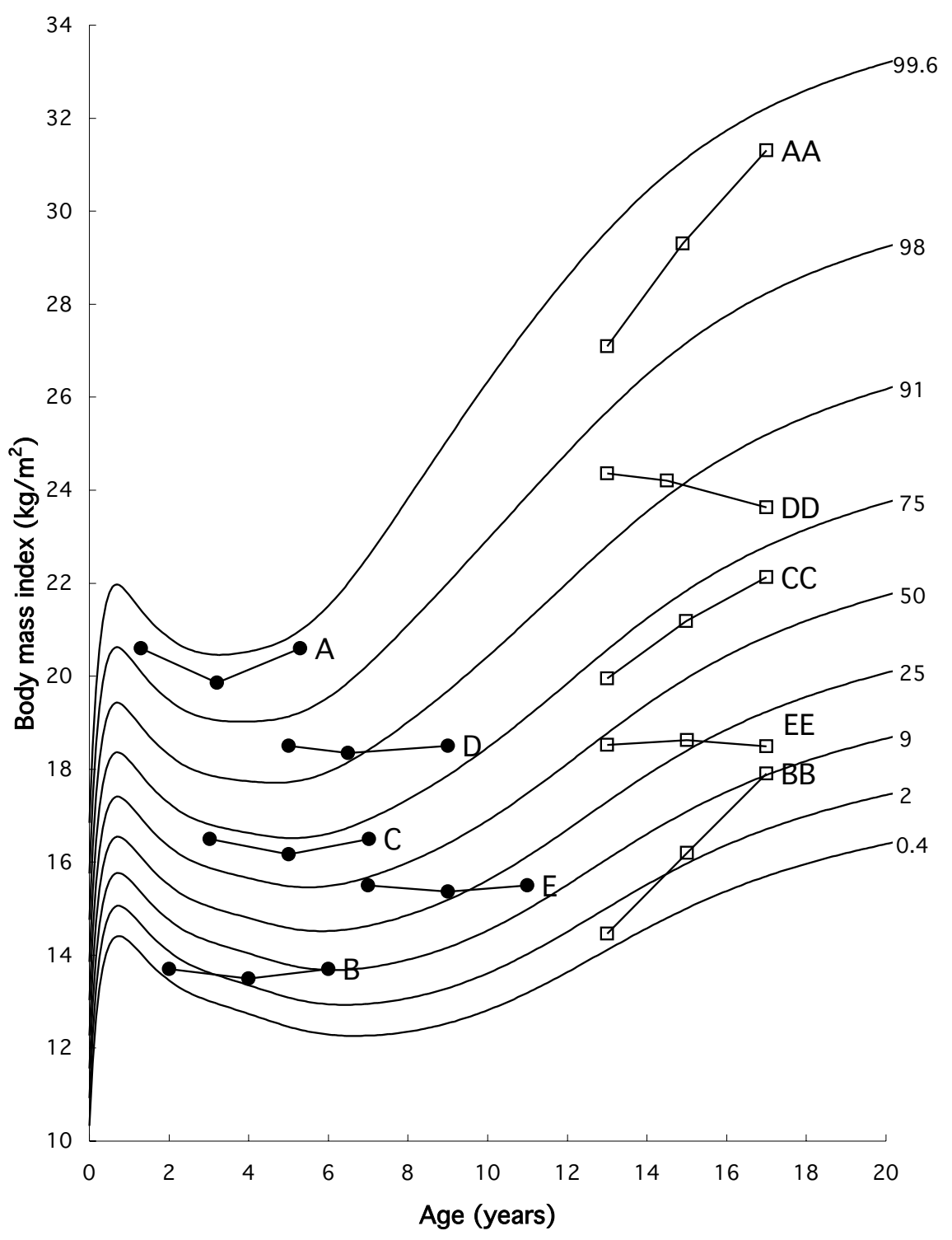

Figure 2

British 1990 girls BMI chart. The adiposity rebound for each of five hypothetical subjects $A$ to $E$, defined by three measurements over four years where the outer two are the same BMI. The older subjects AA to EE show the same patterns of BMI centile crossing as subjects $A$ to $E$ respectively. 


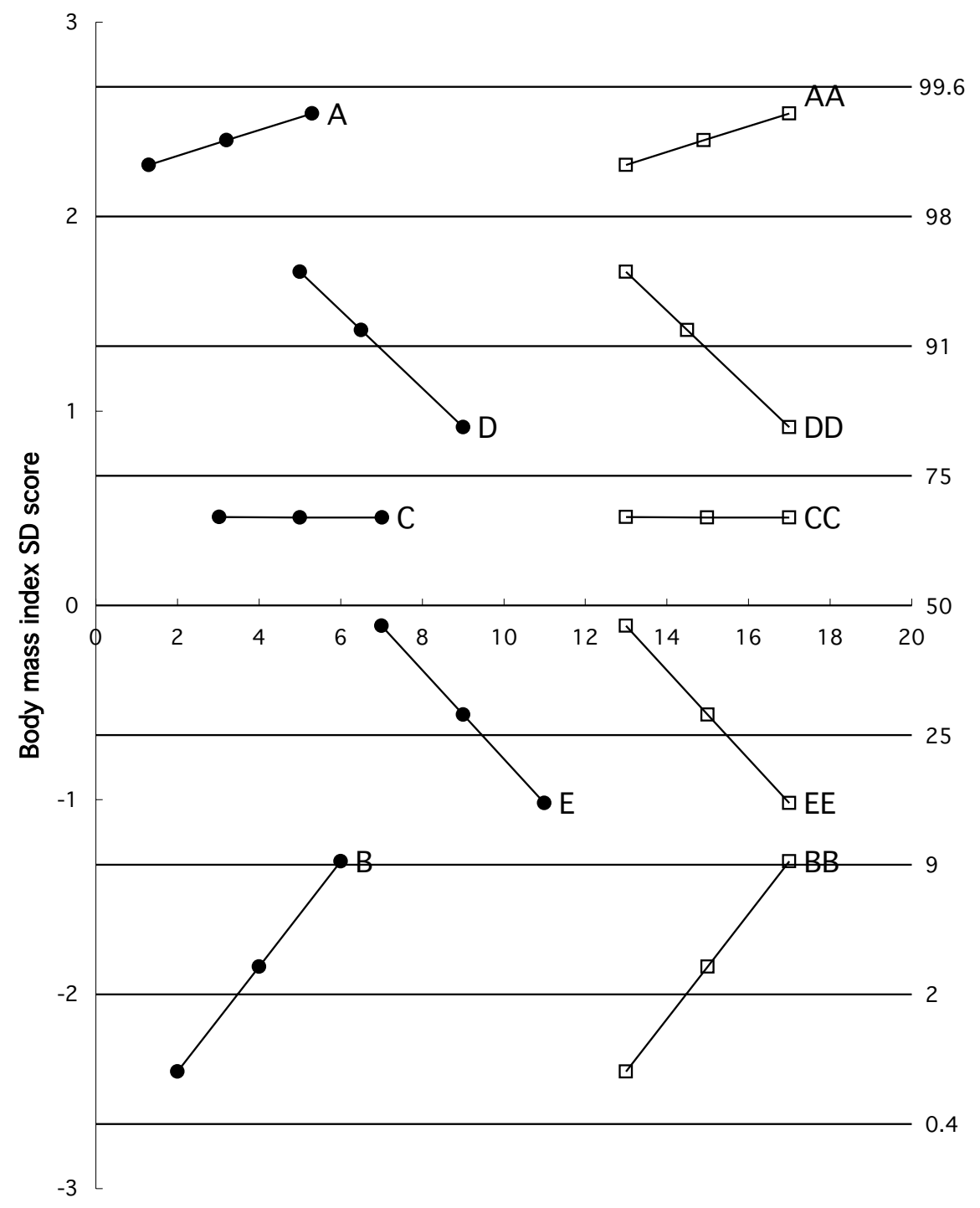

Age (years)

\section{Figure 3}

The data of Figure 2 replotted on the BMI SD score scale. The centiles curves of Figure 2 appear as horizontal and equally spaced straight lines. For each subject $A$ to $E$ the BMI SD score changes linearly over time, indicating a constant rate of centile crossing. Subjects AA to EE show the same patterns as A to E respectively, but starting at age I3. 
rebound and that corresponding to their BMI centile at rebound.

\section{Horse racing and centile crossing}

This immediately explains why an early rebound predicts later obesity. BMI tracks through childhood, $[12,14]$ so that a high BMI centile in early life (particularly at rebound $[12,15]$ ) predicts a relatively high BMI later. In addition a rising BMI centile in early life predicts a higher BMI later for the same reason. So both components separately predict a high BMI later in childhood. This is an example of Peto's "horse racing effect",[16] where childhood is a horse race and race position corresponds to BMI rank. In a horse race, horses near the front of the field and/ or overtaking others have a better chance of winning. This explains why the age at rebound predicts adult BMI when adjusted for BMI at rebound [6] but is no longer predictive when adjusted for BMI at age 7 or 8 [10]. The horse's position early in the race becomes irrelevant once its position later in the race is known.

The association of the timing of rebound with centile crossing arises simply from the curved BMI centile shape at rebound - the centile curves fall before rebound and rise afterwards. But the association of age at rebound with BMI centile at rebound is less easy to explain - why should rebound occur earlier on higher centiles? BMI centile and centile crossing are correlated in that children crossing centiles upwards before rebound are more likely at rebound to be a) on a higher centile, and b) still crossing centiles upwards. Using the racing analogy again, the leading horses at any point in the race have run the fastest to that point and are likely to continue running fast. This implies that the period leading up to rebound is a critical period [7] when children "choose" a trajectory of static, rising or falling centile which predicts both their age and BMI centile at rebound. This in turn means that centile crossing is fundamental to the whole process.

The concept of centile crossing is usually applied to weight rather than BMI, though the two are obviously structurally related. Upward centile crossing of weight in the first 2 years [17] or even 4 months $[18,19]$ of life correlates with later child and adult obesity, so that infancy is also a critical period for later obesity. [20] This raises the possibility that infancy and the period of rebound are a single critical period extending from birth through to midchildhood.

\section{Critical period}

But is it correct to call them critical periods - what exactly is a critical period? Dietz [9] defined it as "a developmental stage in which physiologic alterations increase the later prevalence of obesity". So it needs (i) a physiologic(al) alteration, and (ii) a bounded period with a distinct beginning and end. From the evidence here the connection between early rebound and later fatness is not physiological but statistical - an early rebound is simply upward centile crossing. And upward centile crossing predicts later obesity at whatever age it occurs, not just at rebound - the period is not bounded. So the age at adiposity rebound fails on both counts to qualify as a critical period. This is perhaps why Dietz called it an epiphenomenon [9].

\section{Conclusions}

In conclusion, the age at adiposity rebound reflects the level and rate of change of BMI centile at that age. Upward BMI centile crossing at rebound and other ages in childhood predicts later obesity. So adiposity rebound is not a critical period. The key question for future work on the precursors of child obesity is: what mechanism drives upward BMI centile crossing?

\section{Summary}

- The adiposity rebound is the second rise in body mass index (BMI) that occurs between 3 and 7 years, and an early age at adiposity rebound is known to be a risk factor for later obesity.

- Two aspects of the BMI centile curve, the BMI centile and the rate of BMI centile crossing, determine a child's age at rebound.

- A high centile and upward centile crossing are both associated separately with an early rebound, while a low centile and/or downward centile crossing correspond to a late rebound.

- An early rebound is a risk factor for later fatness because it identifies children whose BMI centile is high and/or crossing upwards. Such children are likely to have a raised BMI later in childhood and adulthood. This is the "horse racing effect".

- The association of centile crossing with later obesity is statistical not physiological, and it applies at all ages not just at rebound, so adiposity rebound cannot be considered a critical period for later obesity.

\section{Abbreviations used}

BMI - body mass index: weight $(\mathrm{kg})$ divided by the square of height $(\mathrm{m})$

\section{Competing interests}

I have no competing interests.

\section{Authors' contributions}

TJC conceived of the study, did the analysis and wrote the manuscript. 


\section{Acknowledgements}

I am grateful to Elina Hypponen, Susan Jebb, Tessa Parsons, Andrew Prentice, Atul Singhal, Russell Viner and Jonathan Wells for their comments on earlier drafts of the paper. The two reviewers, David Freedman and Marie Françoise Rolland-Cachera, made valuable suggestions to improve the submitted paper.

\section{References}

I. Anon: Childhood obesity: an emerging public-health problem. Lancet 200I, 357:1989.

2. Dietz WH: The obesity epidemic in young children - Reduce television viewing and promote playing. British Medical Journal 200I, 322:313-314.

3. Rolland-Cachera MF, Deheeger M, Bellisle F, Sempé M, GuilloudBataille $M$, Patois E: Adiposity rebound in children: a simple indicator for predicting obesity. American Journal of Clinical Nutrition 1984, 39:129-135.

4. Rolland-Cachera MF, Deheeger M, Bellisle F: The adiposity rebound: its contribution to obesity in children and adults. In Obesity in childhood and adolescence Edited by: Chen C, Dietz WH. Philadelphia: Lippincott Williams and Wilkins; 2002:99-II3.

5. Rolland-Cachera MF, Deheeger M, Guilloud-Bataille M, Avons P, Patois $E$, Sempé $M$ : Tracking the development of adiposity from one month of age to adulthood. Annals of Human Biology 1987, I 4:219-229.

6. Whitaker RC, Pepe MS, Wright JA, Seidel KD, Dietz WH: Early adiposity rebound and the risk of adult obesity. Pediatrics I998, I 0 I:E5.

7. Dietz WH: Critical periods in childhood for the development of obesity. American Journal of Clinical Nutrition 1994, 59:955-959.

8. Cameron N, Demerath EW: Critical periods in human growth and their relationship to diseases of aging. Yearbook of Physical Anthropology 2002, 45: I59-184.

9. Dietz WH: "Adiposity rebound": reality or epiphenomenon? Lancet 2000, 356:2027-2028.

10. Freedman DS, Khan LK, Serdula MK, Srinivasan SR, Berenson GS: $B M I$ rebound, childhood height and obesity among adults: the Bogalusa Heart Study. International Journal of Obesity 200I, 25:543-549.

II. Cole TJ, Freeman JV, Preece MA: Body mass index reference curves for the UK, 1990. Archives of Disease in Childhood 1995, 73:25-29.

12. Williams S, Davie G, Lam F: Predicting BMI in young adults from childhood data using two approaches to modelling adiposity rebound. International Journal of Obesity 1999, 23:348-354.

13. Cole TJ: Do growth chart centiles need a face lift? British Medical Journal 1994, 308:641-642.

14. Karlberg J, Kwan CW, Albertsson-Wikland K: Reference values for change in body mass index from birth to 18 years of age. Acta Paediatrica 2003, 92:648-652.

15. Siervogel RM, Roche AF, Guo S, Mukherjee D, Chumlea WC: Patterns of change in weight/stature 2 from 2 to 18 years: Findings from long-term serial data for children in the Fels longitudinal growth study. International Journal of Obesity 1991, I 5:479-485.

16. Peto R: The horse-racing effect. Lancet 198I, 2:467-468.

17. Ong KK, Ahmed ML, Emmett PM, Preece MA, Dunger DB: Association between postnatal catch-up growth and obesity in childhood: prospective cohort study. British Medical Journal 2000, 320:967-971.

18. Stettler N, Zemel BS, Kumanyika S, Stallings VA: Infant weight gain and childhood overweight status in a multicenter, cohort study. Pediatrics 2002, 109:194-199.

19. Stettler N, Kumanyika SK, Katz SH, Zemel BS, Stallings VA: Rapid weight gain during infancy and obesity in young adulthood in a cohort of African Americans. American Journal of Clinical Nutrition 2003, 77:1374-1378.

20. Yanovski JA: Rapid weight gain during infancy as a predictor of adult obesity. American Journal of Clinical Nutrition 2003, 77:|350-|35|.

\section{Pre-publication history}

The pre-publication history for this paper can be accessed here:

http://www.biomedcentral.com/1471-2431/4/6/prepub
Publish with Biomed Central and every scientist can read your work free of charge

"BioMed Central will be the most significant development for disseminating the results of biomedical research in our lifetime. "

Sir Paul Nurse, Cancer Research UK

Your research papers will be:

- available free of charge to the entire biomedical community

- peer reviewed and published immediately upon acceptance

- cited in PubMed and archived on PubMed Central

- yours - you keep the copyright

Submit your manuscript here:

http://www.biomedcentral.com/info/publishing_adv.asp
BioMedcentral 